\title{
Electrospun alginate nanofibres as potential bio-sorption agent of heavy metals in water treatment
}

\author{
T. C. Mokhena ${ }^{1,2}$, N. V Jacobs ${ }^{1,3}$, A. S. Luyt ${ }^{4 *}$ \\ ${ }^{1}$ CSIR Materials Science and Manufacturing, Polymers and Composites, Port Elizabeth, South Africa \\ ${ }^{2}$ Department of Chemistry, University of the Free State (Qwaqwa Campus), Phuthaditjhaba, South Africa \\ ${ }^{3}$ Department of Chemistry, Nelson Mandela Metropolitan University, Port Elizabeth, South Africa \\ ${ }^{4}$ Center for Advanced Materials, Qatar University, Doha, Qatar
}

Received 2 January 2017; accepted in revised form 12 March 2017

\begin{abstract}
This paper reports on the potential of electrospun alginate nanofibre membranes to be used for the bio-sorption of heavy metals from aqueous solutions. Poly(ethylene oxide) (PEO) and its blends were electrospun at an applied voltage of $1-1.3 \mathrm{kV} / \mathrm{cm}$ and a solution flow rate of $0.8 \mathrm{~mL} \cdot \mathrm{hr}^{-1}$. The electrospinnability of the nanofibre blends was enhanced by storing the blend solutions in a controlled environmental chamber. The electrospun nanofibre membranes were washed with calcium chloride to remove PEO. Beadless nanofibres with average diameters of $114 \mathrm{~nm}$ and a surface area of $18.03 \mathrm{~m}^{2} \cdot \mathrm{g}^{-1}$ were obtained. Fourier transform infra-red (FTIR) spectroscopy and thermogravimetric analysis (TGA) confirmed the removal of PEO after washing with calcium chloride. The adsorption behaviour of the nanofibrous membranes was investigated using $\mathrm{Cu}(\mathrm{II})$ as model metalloid at different concentrations $\left(0-1000 \mathrm{mg} \cdot \mathrm{L}^{-1}\right)$, temperatures $\left(25,40\right.$, and $\left.60^{\circ} \mathrm{C}\right)$ and $\mathrm{pH}$ values (2-6). The Langmuir isotherm better presented the equilibrium experimental data than the Freundlich model. The electrospun alginate membranes displayed a maximum monolayer sorption capacity $\left(Q_{0}\right)$ of $15.6 \mathrm{mg} \cdot \mathrm{g}^{-1}$ at a $\mathrm{pH}$ of 4 . In a competitive adsoption experiment the removal of metal ions in a mixture followed the order $\mathrm{Cu}>\mathrm{Ni}>\mathrm{Cd}>\mathrm{Co}$.
\end{abstract}

Keywords: polymer membranes, electrospun alginate, copper adsorption, water treatment

\section{Introduction}

One of the major problems of this century is the environmental pollution resulting from industrial activities such as metal finishing, mining, electroplating, painting, dying, photography, surface treatment, and printed circuit board manufacture [1-4]. These activities release large quantities of heavy metals into the environment, which poses a threat to the whole ecosystem (terrestrial and aquatic environments) [5]. The persistence of the metal ions in the ecosystem and their non-biodegradability necessitates suitable and cheaper alternative methods for their removal $[1,4]$. Various techniques have been employed for this purpose, including chemical precipitation, reverse osmosis, electro-dialysis, membrane separation and solvent extraction $[5,6]$. These techniques are usually associated with high cost and energy, and some are time consuming [5].The adsorption method is considered as one of the most effective methods due to its simplicity, high efficiency, economic feasibility, easy recovery and reuse of the adsorbents [3].

There are two main mechanisms associated with the adsorption method, namely physisorption or chemisorption. In most cases both these mechanisms are involved during adsorption. The most important properties of any adsorbent are a large surface area and the availability of functional groups. A number of researchers investigated nanofibre membranes as adsorbents of heavy metal ions from various sources [7-11]. Nanofibre membranes prepared by electrospinning

$\overline{{ }^{*} \text { Corresponding author, e-mail: aluyt@qu.edu.qa }}$

(C) BME-PT 
are especially important due to their unique properties such as large surface area to volume ratio, high porosity, and malleability $[4,12]$. Haider and Park [13] prepared electrospun chitosan nanofibre membranes for the adsorption of copper $(\mathrm{Cu}(\mathrm{II}))$ and lead $(\mathrm{Pb}(\mathrm{II}))$. They reported that the data fitted the Langmuir model well, with a monolayer adsorption capacity for $\mathrm{Cu}(\mathrm{II})$ of $485.44 \mathrm{mg} \cdot \mathrm{g}^{-1}$ and for $\mathrm{Pb}(\mathrm{II})$ of $263.15 \mathrm{mg} \cdot \mathrm{g}^{-1}$. According to the authors these values were 6-10 times higher than the values of chitosan microspheres reported in the literature.

A wide variety of low cost adsorbents such as algae, alginate, chitosan, fungi, peanut husks, and lignin were studied to evaluate their potential as viable alternatives to the mostly used expensive adsorbents such as activated carbon [14]. Among these adsorbents, alginate received considerable interest due to its potential to gel when it comes in contact with metal ions. This property has been exploited to adsorb different metal ions from aqueous media $[3,5,15,16]$. Alginate is one of the most abundant polysaccharides, usually extracted from seaweeds (brown algae), and it is composed of mannuronate $(\mathrm{M})$ and guluronate $(\mathrm{G})$ acid residues. These residues may vary in sequence and $\mathrm{M} / \mathrm{G}$ ratio along the polymer, depending on the species and the nature of growth.

To our knowledge there is no study based on electrospun alginate nanofibres as metal adsorbent. The aim of this study was therefore to prepare calcium alginate nanofibre membranes by electrospinning and to investigate its application as an adsorbent for the removal of copper, a model metalloid from aqueous solutions. The effect of contact time, initial metal concentration, and temperature was evaluated to find the optimal conditions for maximum metal adsorption capacity. The electrospinnability of alginate from its aqueous solution is still a problem, and poly(ethylene oxide) (PEO) was therefore used to facilitate its spinnability.

\section{Experimental}

\subsection{Materials}

Sodium alginate (SA) (Sigma, viscosity $\left(25^{\circ} \mathrm{C}, 2 \mathrm{wt} \%\right.$ aqueous solution) $=2000 \mathrm{cP}$, medium viscosity, $M_{\mathrm{w}}=$ $100 \mathrm{kDa}$ ), poly(ethylene oxide) (PEO) (Sigma, $M_{\mathrm{w}}=$ $2000 \mathrm{kDa})$ and copper sulphate $\left(\mathrm{CuSO}_{4}\right)$ (Ibhayi Suppliers).

\subsection{Preparation of $\mathrm{PEO}$ /alginate nanofibre membranes}

Sodium alginate (SA) and PEO were separately dissolved in deionized water for 24 hours to ensure complete dissolution. The SA (3 wt $\%$ ) and PEO (3 wt $\%$ ) aqueous solutions were mixed at a 1:1 ratios and stirred for an additional 4 hours to ensure homogeneity. The alginate solution was aged in an environmental chamber (Binder $\mathrm{GmbH}$ ) set at a temperature of $23 \pm 2{ }^{\circ} \mathrm{C}$ and a humidity of $60 \pm 5 \%$ for 30 days, which improved the electrosinnability of the solutions. Aliquots of the alginate solution were removed at 5 day intervals and mixed with freshly prepared PEO solutions. The mixtures were stirred for 4 hours and then electrospun. Mixtures of freshly prepared alginate and PEO blend solutions were stored under the same conditions as the aged solutions. Aliquots were also removed at 5 day intervals and electrospun. The electrospinning solution flow rate was $0.8 \mathrm{~mL} \cdot \mathrm{hr}^{-1}$. A high voltage of $22 \mathrm{kV}$ was applied to generate electric fields between the tip of the needle capillary and collector over a distance of $17 \mathrm{~cm}$. The obtained bead-free nanofibres were further crosslinked using $\mathrm{CaCl}_{2}$ solution at ambient conditions. The nanofibres were soaked in $80 \%$ ethanol for $5 \mathrm{~min}$ and rinsed with $2 \mathrm{wt} \% \mathrm{CaCl}_{2}$ solution in ethanol for $10 \mathrm{~min}$. The nanofibres were incubated in an aqueous solution of $\mathrm{CaCl}_{2}$ for an hour, and then immersed in deionized water for another hour. The $\mathrm{CaCl}_{2}$ treated membranes were then rinsed with deionized water, followed by washing with absolute ethanol, and dried at room temperature. In the rest of the paper these membranes are designated $\mathrm{CaA}$.

\subsection{Characterization}

A Crison CM 35 conductivity meter and a Brookfield DV-II viscometer were used to measure the conductivity and viscosity of the SA and PEO/SA blend solutions.

The IR spectra of the electrospun nanofibres were obtained in a Perkin Elmer Spectrum 100 FTIR spectrometer equipped with an attenuated total reflection (ATR) accessory with a diamond/ZnSe crystal. The ATR-FTIR spectra were obtained at room temperature with the wavenumber ranging between 500 and $4000 \mathrm{~cm}^{-1}$, using 16 scans and $4 \mathrm{~cm}^{-1}$ resolution. 
The thermal stability of the nanofibre membranes was analysed with a Perkin Elmer TGA7 thermogravimetric analyzer. Samples with masses in the range of 10 to $20 \mathrm{mg}$ were heated under a nitrogen flow of $20 \mathrm{~mL} \cdot \mathrm{min}^{-1}$ from 30 to $600^{\circ} \mathrm{C}$ at a heating rate of $10^{\circ} \mathrm{C} \cdot \mathrm{min}^{-1}$, and the corresponding mass loss was recorded.

The morphologies of the electrospun nanofibres were determined by an FEI Quanta 200 scanning electron microscope (SEM). About 100 readings per sample were taken to measure the average fibre diameter. The specific surface area, as well as pore size and volume, were determined using the BrunauerEmmett-Teller (BET) method.

\subsection{Batch adsorption experiments}

The copper $(\mathrm{Cu}(\mathrm{II}))$ adsorption onto the electrospun alginate nanofibre membranes was studied under different contact times, concentrations, $\mathrm{pH}$ and temperatures. Tests solutions were prepared by dissolving $\mathrm{CuSO}_{4}$ in deionized water. The electrospun alginate nanofibre membranes $(\sim 0.25 \mathrm{~g})$ were placed in the $50 \mathrm{~mL}$ metal ion solutions of different concentrations ranging from 0 to $1000 \mathrm{mg} \cdot \mathrm{L}^{-1}$. The concentrations of heavy metal ions in the adsorption medium were measured using atomic absorption spectroscopy (Varian Spectra AAS 220Z). The amount of the adsorbed metal ions, $Q_{\mathrm{e}}\left[\mathrm{mg} \cdot \mathrm{g}^{-1}\right]$, was calculated using Equation (1):

$Q_{\mathrm{e}}=\frac{\left(C_{0}-C_{\mathrm{e}}\right) V}{m}$

where $Q_{\mathrm{e}}\left[\mathrm{mg} \cdot \mathrm{g}^{-1}\right]$ is the amount of metal adsorbed on the adsorbent at equilibrium, $C_{0}\left[\mathrm{mg} \cdot \mathrm{L}^{-1}\right]$ is the initial solution concentration, $C_{\mathrm{e}}\left[\mathrm{mg} \cdot \mathrm{L}^{-1}\right]$ is the final concentration of metalloid in the solution at equilibrium, $m[\mathrm{~g}]$ is the mass of the adsorbent used and $V[\mathrm{~L}]$ is the volume of the metalloid solution. The removal percentage [\%] of metal ion from aqueous solution at different initial concentrations was calculated using Equation (2):

$R[\%]=\frac{C_{0}-C_{\mathrm{e}}}{C_{0}} \cdot 100$

For the adsorption experiments, the electrospun alginate membrane $(0.25 \mathrm{~g})$ was placed in a stoppered conical flask $(100 \mathrm{~mL})$ kept in a continuously stirred silicon oil bath $(150 \mathrm{rpm})$ at a fixed temperature $(25$, 40 or $60^{\circ} \mathrm{C}$ ) for 3 hours.

The nanofibres were regenerated by washing with ethylenediaminetetraacetic acid (EDTA) and then rinsed with deionized water followed by drying in a vacuum oven at $60^{\circ} \mathrm{C}$.

To evaluate the selectivity of the electrospun alginate nanofibre membrane, a multi-component solution containing $100 \mathrm{mg} \cdot \mathrm{L}^{-1}$ each of $\mathrm{Cu}(\mathrm{II}), \mathrm{Cd}(\mathrm{II}), \mathrm{Ni}(\mathrm{II})$ and $\mathrm{Co}(\mathrm{II})$, and with a $\mathrm{pH}$ of 4 , was prepared. The electrospun nanofibre membrane $(0.25 \mathrm{~g})$ was placed in a stoppered conical flask $(100 \mathrm{~mL})$ stirred continuously at $150 \mathrm{rpm}$ for 3 hours. The removal percentage was calculated using Equation (2).

\section{Results and discussion}

\subsection{Electrospun alginate nanofibre membranes}

Although electrospinning has been proven to be a feasible and a simple technique to consistently produce long nanofibres from different polymers, its applicability to produce beadless nanofibres is determined by voltage, tip-to-collector distance, feeding rate, solution concentration and viscosity. Table 1 shows the properties of SA, PEO, a freshly prepared $\mathrm{PEO} / \mathrm{SA}$ blend, and the blends aged under controlled environmental conditions. As expected, PEO, a nonionic polymer, showed very low conductivity and a moderate viscosity compared to pure alginate due to the absence of charged groups along the PEO chains.

Table 1. Properties of SA, PEO, and the freshly prepared and aged PEO/SA blends

\begin{tabular}{|c|c|c|c|c|}
\hline Sample & $\begin{array}{c}\text { Viscosity } \\
{[\mathrm{cP}]}\end{array}$ & $\begin{array}{c}\text { Conductivity } \\
{\left[\mathrm{mS} \cdot \mathrm{cm}^{-1}\right]}\end{array}$ & $\begin{array}{c}\text { Diameter } \\
\text { [nm] }\end{array}$ & Morphology \\
\hline PEO & $1192 \pm 50$ & $0.10 \pm 0.00$ & $313 \pm 86$ & Bead-free \\
\hline $\mathrm{SA}$ & $12382 \pm 167$ & $5.60 \pm 0.01$ & - & Droplets \\
\hline $\mathrm{PEO} / \mathrm{SA}$ & $4905 \pm 90$ & $2.28 \pm 0.01$ & - & Droplets \\
\hline $\mathrm{PEO} / \mathrm{SA}$ (5 days) & $4525 \pm 3$ & $2.75 \pm 0.03$ & $83 \pm 26$ & Beaded \\
\hline PEO/SA (10 days) & $3517 \pm 0$ & $2.77 \pm 0.03$ & $114 \pm 49$ & Beaded \\
\hline PEO/SA (15 days) & $2516 \pm 23$ & $2.74 \pm 0.04$ & $112 \pm 47$ & Bead-free \\
\hline PEO/SA (20 days) & $2111 \pm 8$ & $2.80 \pm 0.04$ & $132 \pm 55$ & Bead-free \\
\hline PEO/SA (25 days) & $1117 \pm 0$ & $2.80 \pm 0.08$ & $171 \pm 69$ & Beaded \\
\hline PEO/SA (30 days) & $1088 \pm 8$ & $3.10 \pm 0.06$ & $178 \pm 75$ & Beaded \\
\hline
\end{tabular}


SA displayed both high conductivity and viscosity that can be ascribed to its inherent anionic polyelectrolytic character and the strong inter- and intramolecular forces [16]. Mixing of SA and PEO increased both the viscosity and conductivity 4 and 22 fold, respectively. The solution viscosity of the aged PEO/SA blend decreased gradually with an increase in the number of storage days. This can be related to the aqueous hydrolysis of alginate which causes the fractionation of the glycosidic bonds and results in a significant decrease in viscosity $[17,18]$. These glycosidic bonds serve as a strong intra- and intermolecular network between the alginate chains. The conductivity of the aged blend solutions slightly increased with storage time. This may be due to some dissociated ions from the alginate chains during storage which contributed to the overall conductivity of the solution.

We also found that the viscosity of the solutions played a major role in controlling the morphology of the resulting electrospun nanofibres. A freshly prepared blend of alginate and PEO (stirred for 4 hours followed by spinning) yielded droplets on the collector (Table 1). However, when the PEO/alginate blend solutions were stored for a certain period under controlled environmental conditions, the morphology of the fibres improved, especially after 10 days (Figure 1, Table 1). It is clear from Figure 1 that the electrospinnability was improved from an electrospraying phenomenon that produced droplets, to an electrospinning process that yielded beaded and bead-free nanofibres for the aged samples. Although there was no particular trend in the morphology of the stored electrospun nanofibres, bead-free nanofibres were obtained after 15 and 20 days' ageing (Figures $1 \mathrm{c}$ and 1d), whereafter beaded nanofibres were obtained for longer ageing periods (Figures 1e and 1f). Bhattarai et al. [18] reported that 15 days was the optimum storage time (at ambient conditions) for a $\mathrm{PEO} /$ alginate blend to produce bead-free nanofibres. Though they related this phenomenon to a significant reduction in the viscosity of the solutions, which is also reflected in Table 1, it seems as if there are several factors that could have influenced the solution properties during their storage. One possibility is the interaction between the alginate and PEO during their storage. It is possible that the longer the $\mathrm{PEO} / \mathrm{SA}$ blends are aged, the bigger the chances for the formation of a large number of carboxylate groups due to dissociation of sodium ions from the alginate, as justified by the slight increase in conductivity (Table 1). The resulting carboxylate and sodium ions interacted with the ether group of PEO, resulting in a better interaction between these components; however, this will depend on the number of the carboxylate and sodium ions in the system. To confirm the above-mentioned observations, a solution of alginate alone $(0.025 \mathrm{wt} \%)$ was kept at room temperature without stirring, and a brown sediment was observed after 15 days which may have been due to the dissociated sodium ions from the alginate. In such cases the sodium ions are normally responsible for the dissolution of alginate in water. After 30 days, the solution was saturated and no reaction took place to further dissolve the remainder of the sediment. Similarly, when the 50/50 w/w solution of SA and PEO (0.025 wt\%) was kept at room temperature, there was no segregation in the solution for 30 days. This may be because of interactions between PEO, sodium ions and carboxylate groups from the alginate, via the ether oxygen. This enhanced the interaction between the PEO and SA, which in turn improved the spinnability of the aged blend, independent of storage period and regardless of a decrease in the solution viscosity.

This was proven by studying the influence of alginate degradation in the resulting nanofibres. An aliquot of aged alginate was removed from the alginate solution and mixed with freshly prepared PEO solution followed by electrospinning. The nanofibres of the blends, PEO and the alginate extracted after different periods of time, were successfully fabricated as shown in Figure 2. Beaded and wet nanofibres were obtained after 5, 10 and 15 days (Figures 2a to 2c). From 20 days, only droplets were collected (Figure $2 \mathrm{~d}$ ). This is probably due to a drastic decrease in viscosity of the alginate solution and a lack of strong interaction between the PEO and SA.

Figure 3a shows the FTIR spectra of electrospun $\mathrm{PEO}, 50 / 50 \mathrm{w} / \mathrm{w} \mathrm{PEO} / \mathrm{SA}$ and $\mathrm{CaCl}_{2}$-treated nanofibres $(\mathrm{CaA})$. The characteristic peaks of $\mathrm{PEO}$ were observed at $2881 \mathrm{~cm}^{-1}$ (CH stretching), $1456 \mathrm{~cm}^{-1}\left(\mathrm{CH}_{2}\right.$ wagging), 1100 and $839 \mathrm{~cm}^{-1}$ (C-O-C stretching and bending), and $960 \mathrm{~cm}^{-1}$ corresponding to $\mathrm{CH}_{2}$ rocking and twisting [19]. The addition of alginate into PEO showed new peaks corresponding to alginate at $3358 \mathrm{~cm}^{-1}$ (OH stretching), $1602 \mathrm{~cm}^{-1}$ (COO-asymmetric stretching), $1410 \mathrm{~cm}^{-1}$ (COO- symmetric stretching) $[18,20]$. The $\mathrm{OH}$ and $\mathrm{COO}-$ stretching peaks shifted from 3358 to $3256 \mathrm{~cm}^{-1}$ and 1602 to $1596 \mathrm{~cm}^{-1}$, respectively. This is probably due to the interaction that occurred between the carboxyl and 


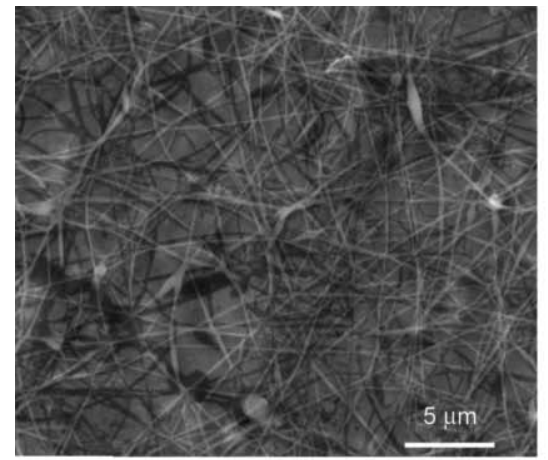

a)

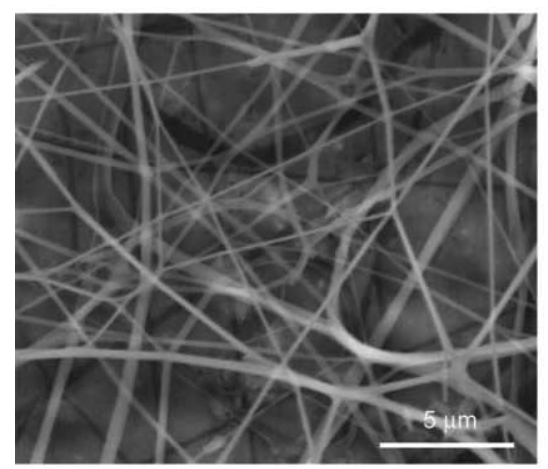

d)

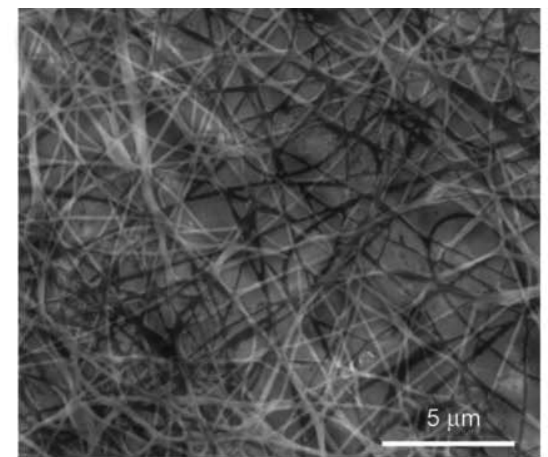

b)

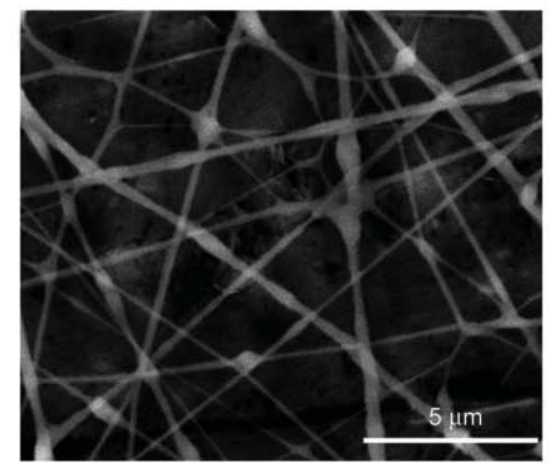

e)

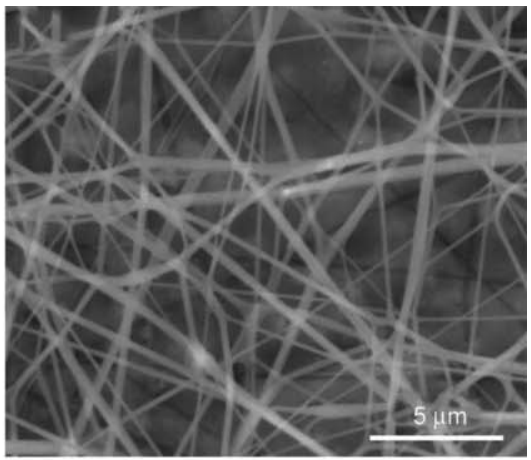

c)

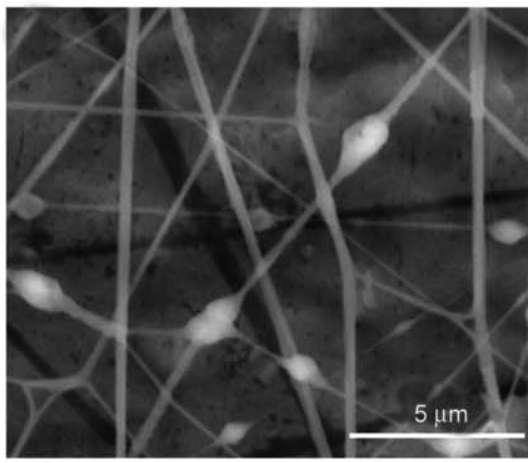

f)

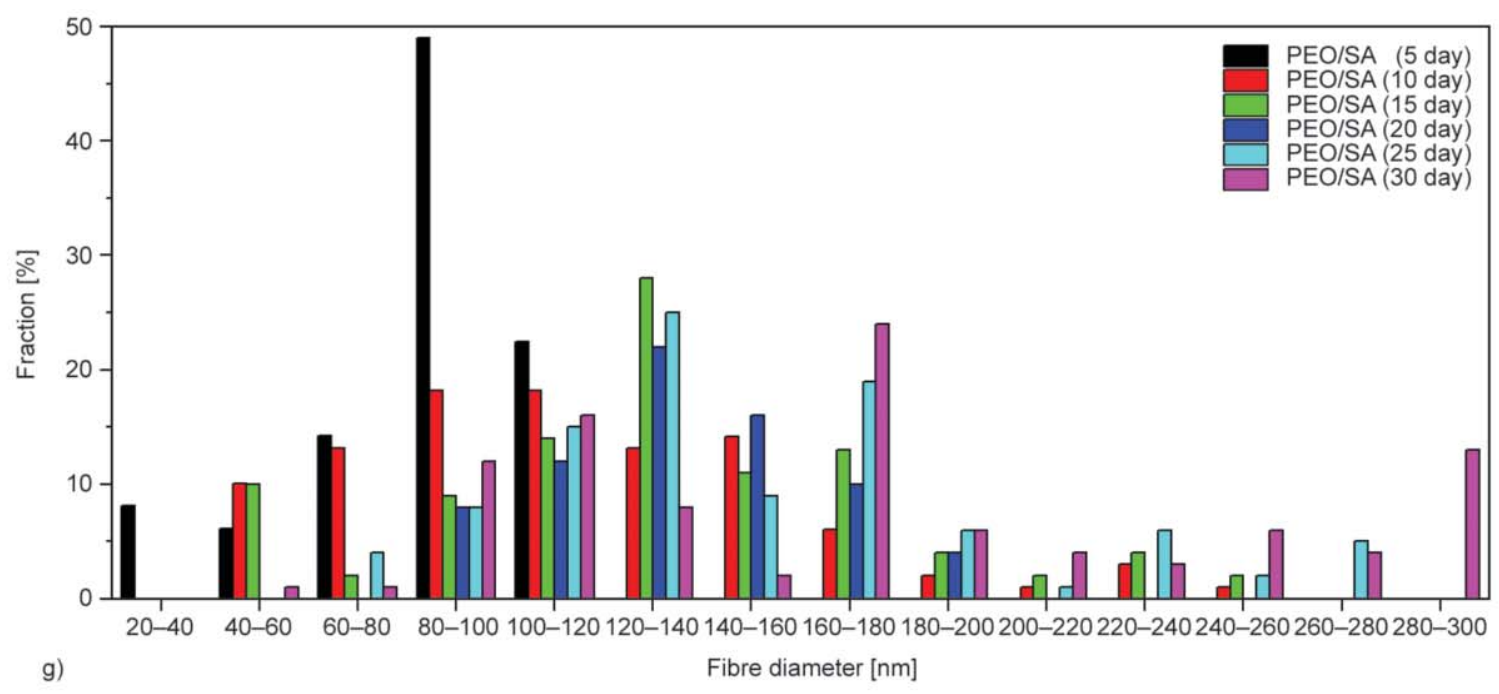

Figure 1. SEM micrographs of the electrospun 50/50 w/w PEO/SA blends aged for (a) 5, (b) 10, (c) 15, (d) 20, (e) 25, and (f) 30 days, with the fibre diameter distribution shown in (g)

hydroxyl groups of alginate and the ether group of PEO through hydrogen bonding. After washing with aqueous calcium solution, all the peaks associated with PEO disappeared. This is attributed to the dissolution of PEO in water during ionic crosslinking. The TGA curves of PEO, PEO/SA blend and calcium alginate $(\mathrm{CaA})$ are shown in Figure $3 \mathrm{~b}$. PEO shows a single degradation step around $400^{\circ} \mathrm{C}$, while the blend shows three degradation steps. The first mass loss below $100^{\circ} \mathrm{C}$ can be related to the evaporation of water. The second step can be associated with thermal degradation of alginate, while the third corresponds to the thermal degradation of PEO. After washing the blend and crosslinking with calcium chloride (CaA), the degradation step corresponding to PEO was not visible (Figure $3 \mathrm{~b}$ ). This is in agreement with the FTIR results and confirmed the complete removal of PEO from the blend.

The average pore size in the fibres was determined as $215 \mathrm{~nm}$, the surface area as $18.03 \mathrm{~m}^{2} \cdot \mathrm{g}^{-1}$, and the average pore volume as $0.96 \mathrm{~cm}^{3} \cdot \mathrm{g}^{-1}$, which indicates that the electrospun alginate membranes were macro-porous. 


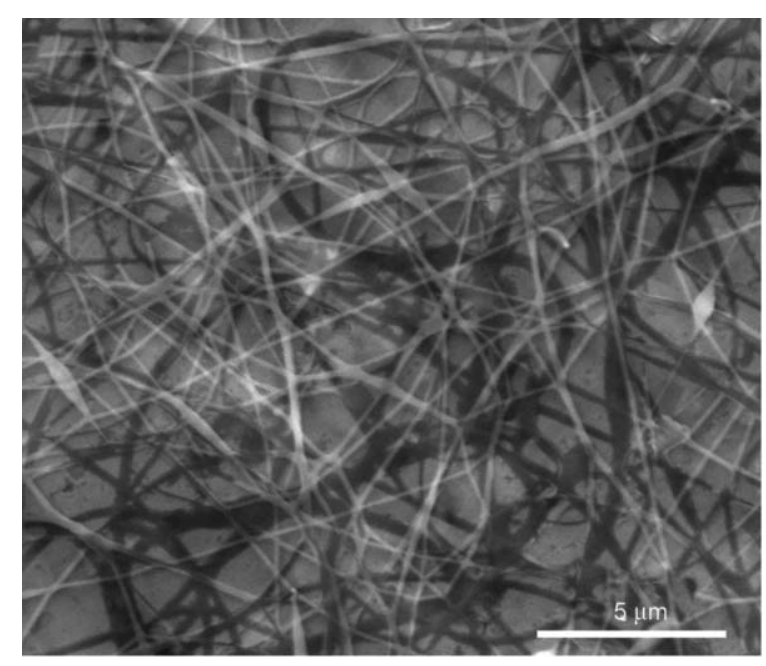

a)

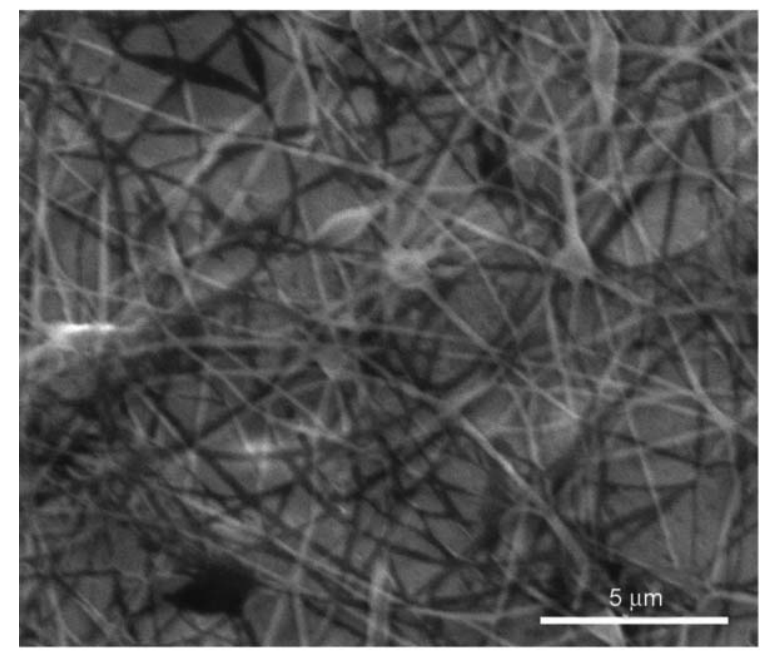

c)

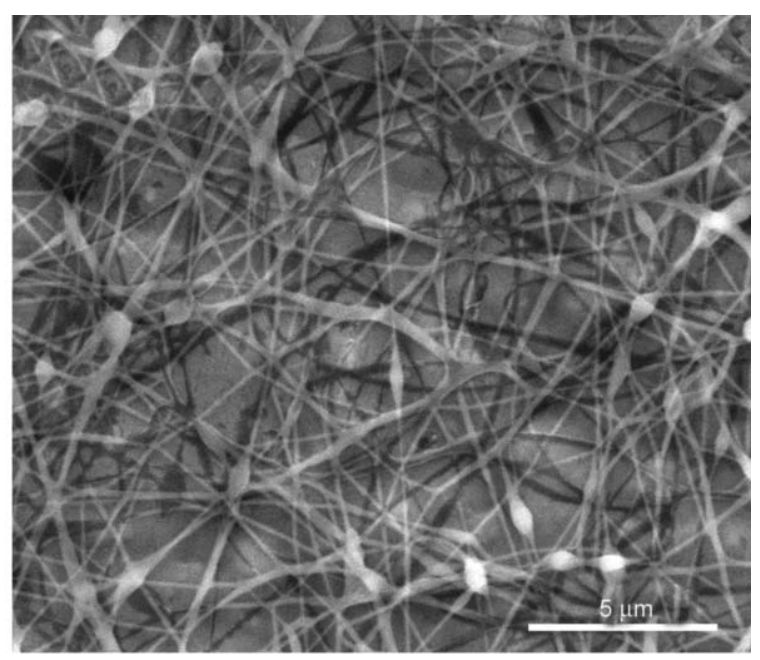

b)

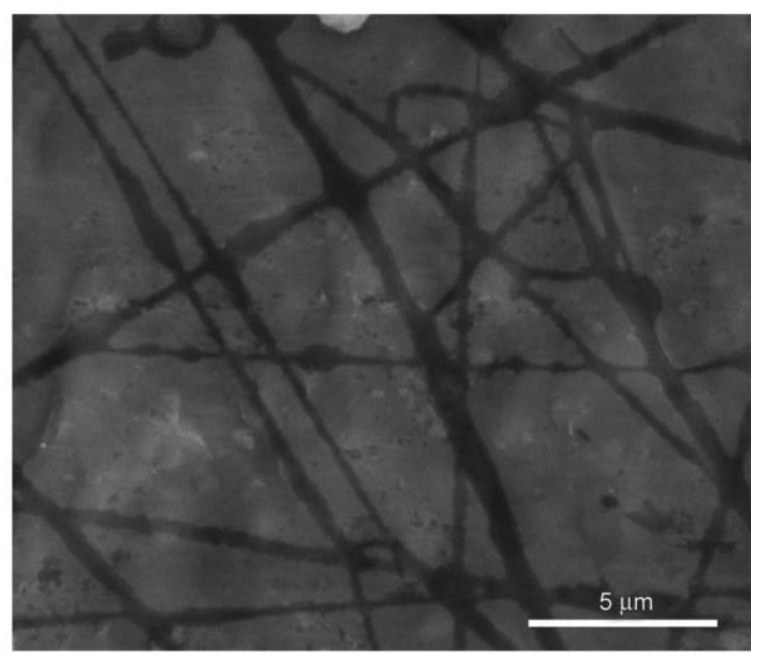

d)

Figure 2. SEM micrographs of 50/50 w/w PEO/SA from SA aliquots extracted after (a) 5, (b) 10, (c) 15 and (d) 20 days
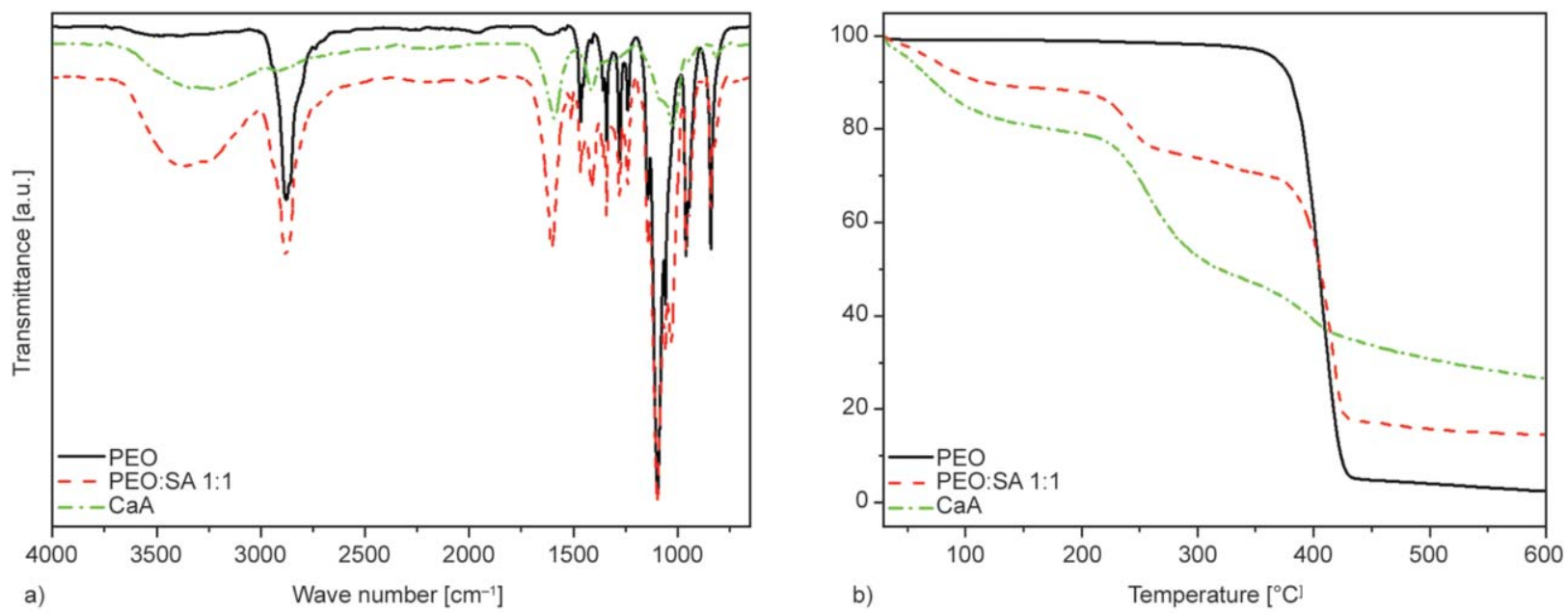

Figure 3. (a) FTIR spectra and (b) TGA curves for electrospun PEO, the blend and the CaA nanofibres

\subsection{Biosorption studies}

\subsubsection{Effect of $\mathbf{p H}$}

In this study, $\mathrm{Cu}(\mathrm{II})$ was selected as a model heavy metal to evaluate the adsorption capacity of the electrospun alginate membranes $(\mathrm{CaA})$. One of the most valuable factors in metal adsorption is the solution $\mathrm{pH}$ since it influences the surface charge of the adsorbent, as well as the degree of ionization [6]. 
For the effect of $\mathrm{pH}$ on the adsorption capacity of $\mathrm{CaA}, 0.05 \mathrm{~g}$ of membrane was immersed in an aqueous solution of $\mathrm{Cu}$ (II) for 3 hours at $25^{\circ} \mathrm{C}$. The $\mathrm{pH}$ values of the metal were kept below 7 to avoid the precipitation of the metal ions [21, 22], and $0.1 \mathrm{M}$ $\mathrm{NaOH}$ and $0.1 \mathrm{M} \mathrm{HCl}$ were used to adjust the $\mathrm{pH}$ values. The adsorption of the electrospun alginate membrane was found to depend on the $\mathrm{pH}$ values as shown in Figure 4. At a pH value of 4 (when compared to a $\mathrm{pH}$ of 2) the $\mathrm{Cu}$ (II) uptake increased from 56 to $79 \%$ and from 49 to $64 \%$ for 100 and $600 \mathrm{mg} \cdot \mathrm{L}^{-1}$ concentrations, respectively. At low $\mathrm{pH}$ values, the binding sites are limited due to the competition between the metal ion $\left(\mathrm{M}^{2+}\right)$ and the high $\mathrm{H}^{+}$ions concentration. As the $\mathrm{pH}$ increases, the $\mathrm{H}^{+}$ions are released from the adsorbent which increases the number of negatively charged active sites available to bind the metal ion, hence the increase in adsorption at a $\mathrm{pH}$ value of 4 . This can be associated with the ionization of carboxyl groups along the alginate chains [3]. The ionised carboxyl groups therefore improve the sorption capacity of the alginate. The $\mathrm{pH}$ of 4 displayed the maximum removal percentage of $\mathrm{Cu}$ (II) ions from the aqueous medium, regardless of the solution concentration (Figure 4). The difference between the metal uptake at low and high concentration may be attributed to the availability of more $\mathrm{Cu}$ (II) ions at higher concentrations, which compete towards the available binding sites on the adsorbent. In addition, the adjustment of the solution $\mathrm{pH}$ using $\mathrm{NaOH}$ may have impeded the uptake of $\mathrm{Cu}$ (II). Sodium hydroxide has a tendency to react with copper ions to form a precipitate; in this case it is possible that the $\mathrm{NaOH}$

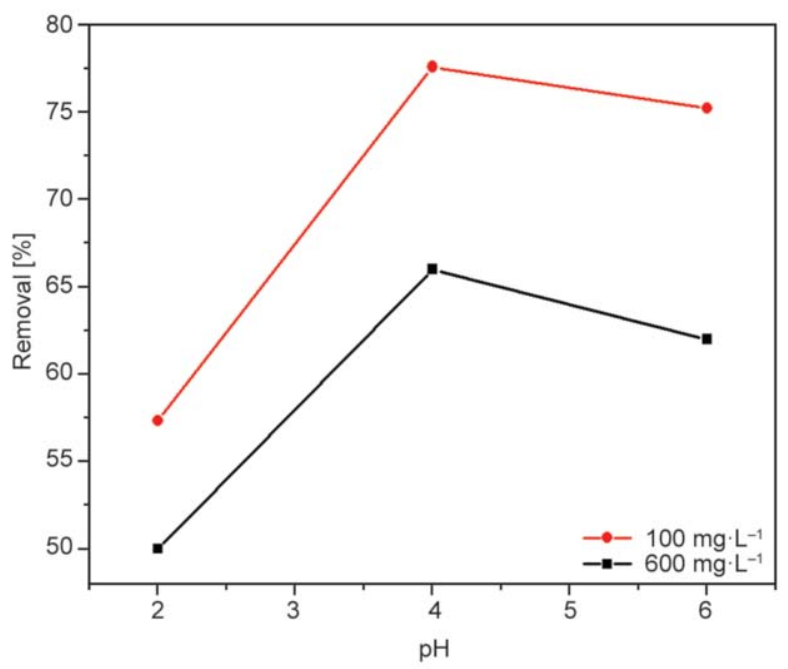

Figure 4. Effect of $\mathrm{pH}$ on the adsorption capacity of the electrospun alginate membrane would rather react with the $\mathrm{Cu}(\mathrm{II})$ ions to form $\mathrm{Cu}(\mathrm{OH})_{2}$ instead of the ions being adsorbed by the alginate, especially at higher $\mathrm{pH}$ and higher $\mathrm{Cu}$ (II) concentrations [21]. Consequently, an aqueous solution with a $\mathrm{pH}$ of 4 was used as an optimum medium throughout the study.

\subsubsection{The effect of contact time}

To study the effect of equilibration time for the electrospun alginate nanofibrous membranes, a solution with a concentration of $100 \mathrm{mg} \cdot \mathrm{L}^{-1}$ and a $\mathrm{pH}$ of 4 , was utilized. For the first 30 minutes, the adsorption was approximately $37 \%$ and gradually increased with an increase in time until the 90th minute (Figure 5), and then levelled off after 120 minutes. Similar behaviour was reported by Aliabadi et al. [10] for the removal of different metal ions using electrospun $\mathrm{PEO} /$ chitosan nanofibres. They found that the equilibration time was 120 minutes. In contrast, Pandey et al. [6] reported that the equilibration time for calcium alginate beads was 7 hours. This could be related to the size of the beads compared to the electrospun alginate nanofibres that have large surface areas and high pore volumes. Therefore, 180 minutes (3 hours) was used throughout the study to ensure maximum adsorption.

\subsubsection{Adsorption isotherms}

The Langmuir and Freundlich isotherms were used to predict the isotherm which best describes the mechanism occurring during the adsorption process. The Langmuir isotherm is often used to describe the adsorption of an adsorbate onto a homogeneous

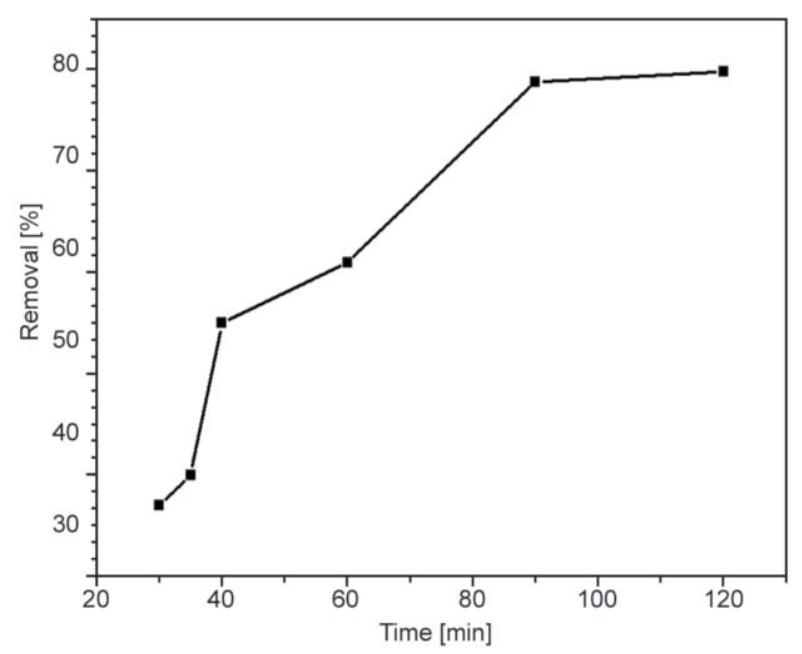

Figure 5. The effect of contact time on the adsorption of $\mathrm{Cu}$ (II) onto alginate nanofibrous membranes 
adsorbent, in which an adsorptive site can only be occupied once [23]. It is described by Equation (3):

$Q_{\mathrm{e}}=\frac{Q_{0} b C_{\mathrm{e}}}{1+b C_{\mathrm{e}}}$

where $Q_{\mathrm{e}}\left[\mathrm{mg} \cdot \mathrm{g}^{-1}\right]$ is the maximum amount of $\mathrm{Cu}(\mathrm{II})$ adsorbed at equilibrium, $Q_{0}\left[\mathrm{mg} \cdot \mathrm{g}^{-1}\right]$ is related to the $\mathrm{Cu}(\mathrm{II})$ monolayer capacity of the adsorbent, $b$ $\left[\mathrm{L} \cdot \mathrm{mg}^{-1}\right]$ represents the energy of adsorption, and $C_{\mathrm{e}}$ $\left[\mathrm{mg} \cdot \mathrm{g}^{-1}\right]$ is the equilibrium $\mathrm{Cu}(\mathrm{II})$ concentration. The linearized Langmuir method is mathematically expressed in Equation (4):

$\frac{C_{\mathrm{e}}}{Q_{\mathrm{e}}}=\frac{C_{\mathrm{e}}}{Q_{0}}+\frac{1}{Q_{0} b}$

The performance of the adsorption behaviour can be predicted by the $R_{\mathrm{L}}$ value which is calculated from Equation (5) [24]:

$R_{\mathrm{L}}=\frac{1}{1+b C_{0}}$

where $C_{0}$ is the initial concentration and $b$ is the Langmuir isotherm constant. If $R_{\mathrm{L}}<1$, it expresses the fact that the adsorption is favourable under the experimental conditions, $R_{\mathrm{L}}=0$ stipulates that the adsorption is irreversible, $R_{\mathrm{L}}=1$ that the adsorption is linear and $R_{\mathrm{L}}>1$ that the adsorption process is unfavourable. In this study, the results indicate that the $R_{\mathrm{L}}$ values were less than zero, indicating a favourable adsorption (Table 2), confirming that the equilibrium isotherms can be described by the Langmuir method. The adsorption of $\mathrm{Cu}(\mathrm{II})$ onto the electrospun alginate membrane at 25,40 , and $60^{\circ} \mathrm{C}$ fitted the Langmuir isotherm quite well (Figure 6). All the plots of $C_{\mathrm{e}} / Q_{\mathrm{e}}$ versus $C_{\mathrm{e}}$ gave linear graphs for all the experimental conditions used in this study. The correlation coefficient $\left(R^{2}\right)$ and Langmuir constants $\left(Q_{0}\right.$ and $\left.b\right)$ were determined from the graphs and are listed in Table 2. The $b$ value is related to the affinity of the adsorbate for the adsorbent [18]. At all the temperatures the $b$ value was too small, which indicates that the $\mathrm{Cu}$ (II) had a weak affinity for electrospun alginate membranes. This may be due to the presence of the $\mathrm{Ca}(\mathrm{II})$, used to crosslink the electrospun alginate nanofibres, occupying most of the available binding sites. In addition, $\mathrm{NaOH}$ was used to adjust the $\mathrm{pH}$ during the solution preparation, leading to some reactions between $\mathrm{Na}$ and $\mathrm{Cu}(\mathrm{II})$ ions and thereby impeding the adsorption of $\mathrm{Cu}$ (II). The maximum monolayer adsorption capacity $\left(Q_{0}\right)$ value decreased with

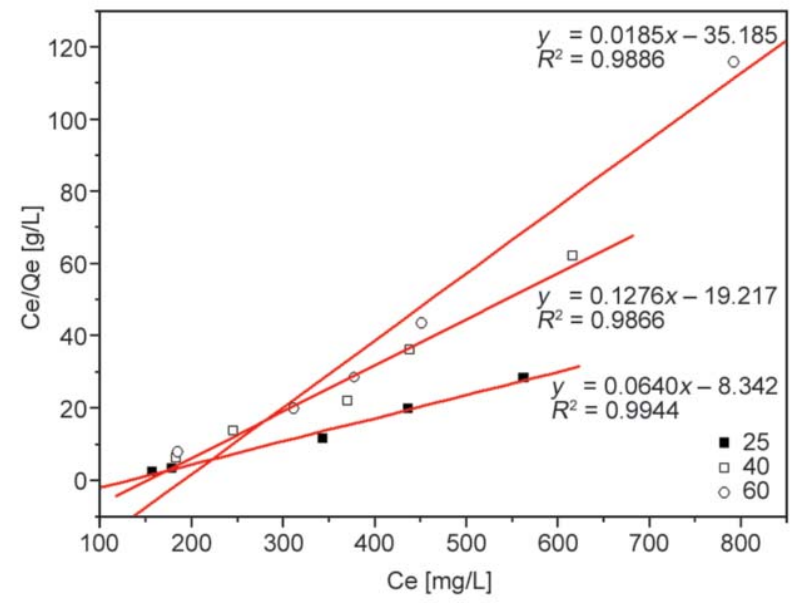

Figure 6. Linearized Langmuir isotherms for the adsorption of $\mathrm{Cu}$ (II) onto electrospun alginate membranes

an increase in temperature. This could be due to the swelling of the alginate nanofibres which caused a blockage of the inner pores of the membranes and impeded the diffusion of the metal ions.

The Freundlich model is usually used to describe the adsorption of the adsorbate onto a heterogeneous surface of an adsorbent [23]. The Freundlich adsorption isotherm is given in Equation (6):

$Q_{\mathrm{e}}=K_{\mathrm{f}}\left(C_{\mathrm{e}}\right)^{\frac{1}{n}}$

where $K_{\mathrm{f}}\left(\left[\mathrm{mg} \cdot \mathrm{g}^{-1}\right] \cdot\left[\mathrm{mg} \cdot \mathrm{L}^{-1}\right]\right)$ is a Freundlich constant for a particular adsorption isotherm and $n$ is the dimensionless Freundlich constant related to the adsorption intensity. The linearized Freundlich model was used in this study to fit the adsorption data. Mathematically, the linearized Freundlich model is expressed in Equation (7):

$\ln Q_{\mathrm{e}}=\ln K_{\mathrm{f}}+\frac{1}{n} C_{\mathrm{e}}$

In the case of the Freundlich model, all the $R$ coefficient values $(R<0.92)$ were lower than the ones displayed by the Langmuir model $(R<0.98)$ (Figure 7, Table 2). This indicates that the Langmuir model better fitted the equilibrium data of $\mathrm{Cu}(\mathrm{II})$ ions than the Freundlich model. The suitability of the Langmuir isotherm compared to the Freundlich isotherm implies that monolayer adsorption was prevalent under the experimental conditions.

Table 3 shows the reported adsorption data of $\mathrm{Cu}$ (II) ions on various adsorbents. Based on these findings, the electrospun alginate membrane $(\mathrm{CaA})$ showed a metal adsorption capacity comparable to or higher than some other types of adsorbents without any further 
Table 2. Kinetic parameters of $\mathrm{Cu}(\mathrm{II})$ adsorption onto electrospun alginate membranes

\begin{tabular}{|c|c|c|c|c|c|c|c|}
\hline \multirow{2}{*}{$\begin{array}{c}\text { Temperature } \\
{\left[{ }^{\circ} \mathbf{C}\right]}\end{array}$} & \multicolumn{3}{|c|}{ Langmuir } & \multicolumn{3}{c|}{ Freundlich } \\
\cline { 2 - 9 } & $\begin{array}{c}\boldsymbol{Q}_{\mathbf{0}} \\
{\left[\mathbf{m g} \cdot \mathbf{g}^{-\mathbf{1}}\right]}\end{array}$ & $\begin{array}{c}\boldsymbol{b} \\
{\left[\mathbf{L} \cdot \mathbf{m g}^{-\mathbf{1}}\right]}\end{array}$ & $\boldsymbol{R}_{\mathbf{L}}$ & $\boldsymbol{R}^{\mathbf{2}}$ & $\begin{array}{c}\boldsymbol{K}_{\mathbf{f}} \\
{\left[\mathbf{m g} \cdot \mathbf{g}^{-1}\right] \cdot\left[\mathbf{m g} \cdot \mathbf{L}^{-\mathbf{1}}\right]}\end{array}$ & $\boldsymbol{n}$ & $\boldsymbol{R}^{\mathbf{2}}$ \\
\hline 25 & 15.6 & -0.0076 & -0.152 to -1.920 & 0.994 & 3780 & 1.082 & 0.989 \\
\hline 40 & 7.83 & -0.0066 & -0.178 to -3.125 & 0.987 & 7412 & 0.899 & 0.961 \\
\hline 60 & 5.41 & -0.0052 & -0.238 to -25.000 & 0.989 & 3298 & 1.431 & 0.915 \\
\hline
\end{tabular}

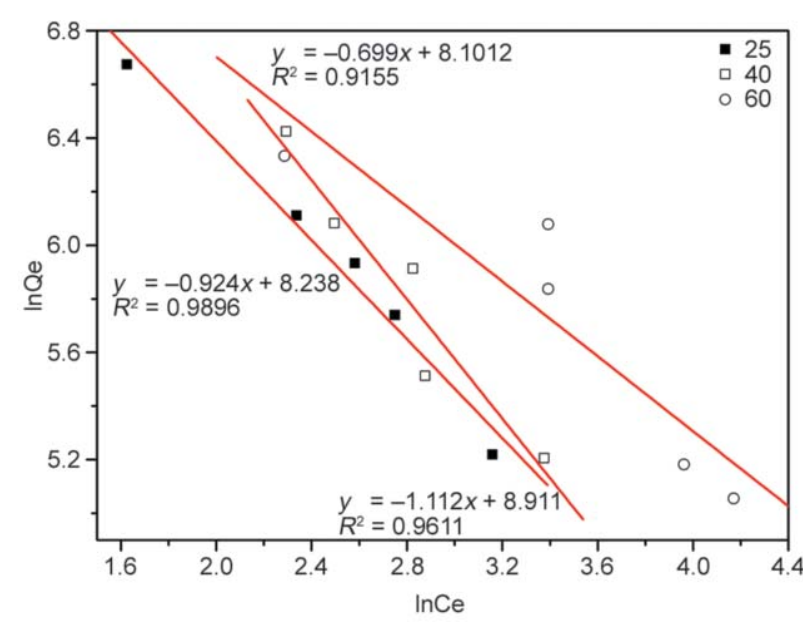

Figure 7. Linearized Freundlich isotherms for the adsorption of $\mathrm{Cu}$ (II) onto electrospun alginate membranes

Table 3. Comparison on the sorption capacity of some adsorbents for $\mathrm{Cu}(\mathrm{II})$

\begin{tabular}{|l|c|}
\hline \multicolumn{1}{|c|}{ Adsorbent } & $\begin{array}{c}\boldsymbol{Q}_{\mathbf{0}} \\
{\left[\mathbf{m g} \cdot \mathbf{g}^{-\mathbf{1}} \text { ] }\right.}\end{array}$ \\
\hline Calcium alginate (beads) [26] & 15.80 \\
\hline Woolkeratose/silk fibroin nanofibers [9] & $2.88 \cdot 10^{-3}$ \\
\hline Grafted thiol cellulose acetate nanofibers [11] & 7.47 \\
\hline Chitosan flakes [27] & 20.92 \\
\hline Humic acid-activated carbon [21] & 5.98 \\
\hline Activated carbon [28] & 38.00 \\
\hline CaA [in this study] & 15.60 \\
\hline
\end{tabular}

functionalization or optimization, and therefore the $\mathrm{CaA}$ electrospun nanofibres have the potential to be used for wastewater treatment.

\subsubsection{Regeneration of electrospun alginate (CaA) membranes}

The regeneration of the adsorbent is of significance for the long-term use, especially for commercial applications. We regenerated the electrospun alginate nanofibres five times using $0.1 \mathrm{M}$ of EDTA. The adsorption/desorption cycles were performed using a $\mathrm{Cu}$ (II) solution with a concentration of $100 \mathrm{mg} \cdot \mathrm{L}^{-1}$, a $\mathrm{pH}$ of 4 and a temperature of $25^{\circ} \mathrm{C}$. There was a very slight decrease in adsorption capacity from the first to the fifth cycle (Figure 8). This could be related

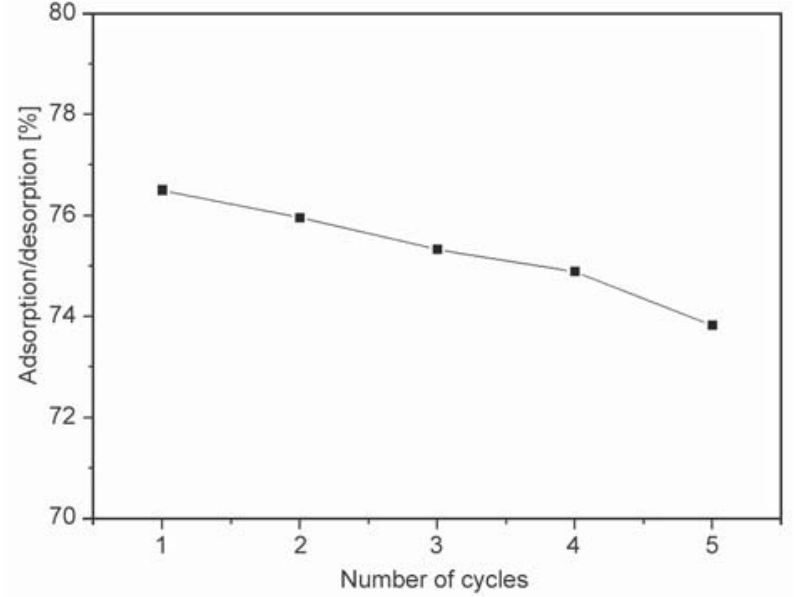

Figure 8. Percentage adsorption of $\mathrm{Cu}$ (II) by the electrospun nanofibres after regeneration for five desorption/ adsorption cycles

to the loss of the adsorbent shape/structure during washing and drying, which caused a deformation in the morphology and thereby reduced the porosity of the electrospun alginate membranes (Figure 9). The washing with EDTA caused the fibres to swell and fuse with each other, destroying the pores in the membrane (compare Figures $9 a$ and $9 b$ ). This reduced the porosity of the membrane by blocking the interior pores which resulted in a gradual decrease in adsorption of the membrane, because of an increase in the number of desorptions. Electrospun alginate nanofibrous membranes from seaweeds can be reused without a significant loss in adsorption capacity.

\subsubsection{Competetive adsorption}

The competitive adsorption of the metals in a multicomponent solution containing four metal ions $\left(\mathrm{Cu}^{2+}\right.$, $\left.\mathrm{Ni}^{2+}, \mathrm{Co}^{2+}, \mathrm{Cd}^{2+}\right)$ was also investigated. The removal percentages were $39.2,37.1,25.3$ and $21.8 \%$ for $\mathrm{Cu}(\mathrm{II}), \mathrm{Ni}(\mathrm{II}), \mathrm{Cd}(\mathrm{II})$, and $\mathrm{Co}(\mathrm{II})$, respectively. The membrane showed a higher affinity for $\mathrm{Cu}$ (II) and $\mathrm{Ni}(\mathrm{II})$, which could be explained by the hard acidbase theory which states that hard acids have a strong affinity for hard bases, whereas soft acids prefer soft bases [3,29]. Both $\mathrm{Cu}^{2+}$ and $\mathrm{Ni}^{2+}$ are referred to as intermediate acids, whereas $\mathrm{Co}^{2+}$ and $\mathrm{Cd}^{2+}$ are 


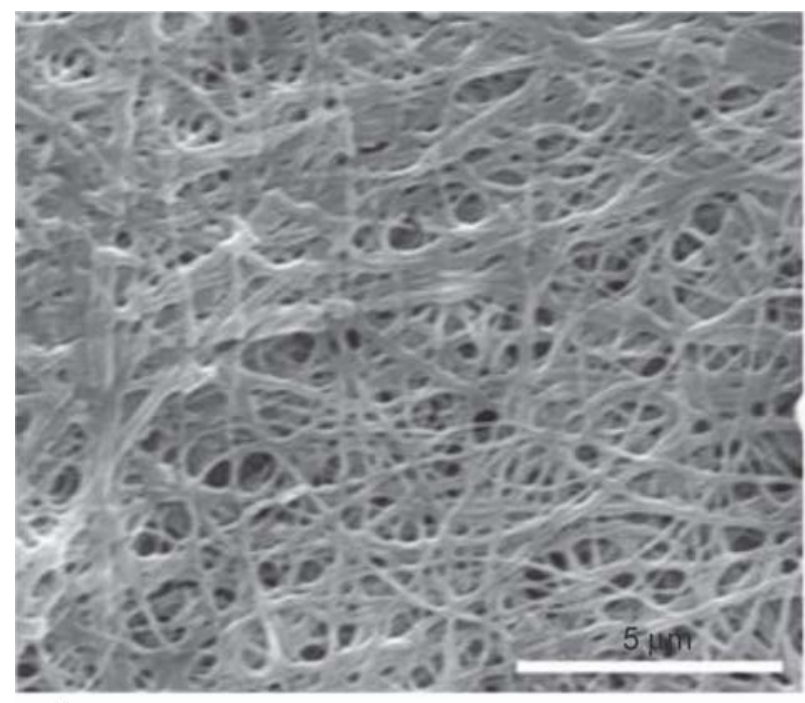

a)

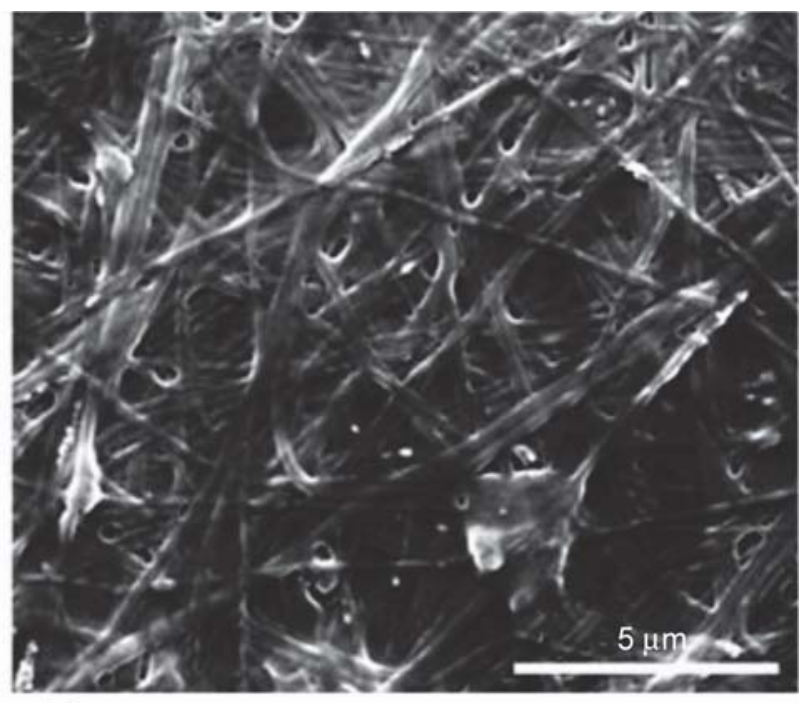

b)

Figure 9. Micrographs of electrospun alginate nanofibres $(\mathrm{CaA})(\mathrm{a})$ before adsorption and (b) after the first adsorption

referred to as soft acids [3, 29]. In view of this the membrane could possibly be classified as an 'intermediate' carboxylate base.

\section{Conclusions}

PEO/SA blends were successfully electrospun after their storage under controlled conditions. The storage conditions were found to play a significant role in the degradation of the alginate, which in turn influenced the electrospinnability of the nanofibre blends. Similar to previous reports, this study proved that environmental conditions are one of the critical parameters that influence the electrospinning process. In this case, the optimal number of storage days ranged between 10 and 20, and both a reduction in viscosity and the formation of a large number of carboxylate groups contributed in facilitating the electrospinning process of the alginate nanofibre blends. It was further found that not only viscosity played a major role in the morphology of the resulting alginate nanofibres, but also the interactions between PEO and the alginate which further improved over time.

The adsorption studies showed that the electrospun calcium alginate nanofibrous membranes, with large surface areas and the presence of both carboxyl and hydroxyl groups, were efficient in the removal of copper ions from aqueous solutions. The membrane showed a maximum metal adsorption capacity of $15.6 \mathrm{mg} \cdot \mathrm{g}^{-1}$ at $25^{\circ} \mathrm{C}$ and a $\mathrm{pH}$ of 4 , and it maintained a reasonable metal adsorption capacity over five recycling intervals. The competitive adsorption of the metal ions followed the order $\mathrm{Cu}>\mathrm{Ni}>\mathrm{Cd}>\mathrm{Co}$, which was in line with the hard-soft-acid-base theory. Therefore, the electrospun alginate nanofibrous membranes proved to be a suitable material for potential application in wastewater treatment.

\section{Acknowlegdements}

The authors would like to thank the Professional Development Programme of the Department of Science and Technology - National Research Foundation (DST-NRF) of South Africa for their financial support.

\section{References}

[1] Salam O. E. A., Reiad N. A., ElShafei M. M.: A study of the removal characteristics of heavy metals from wastewater by low-cost adsorbents. Journal of Advanced Research, 2, 297-303 (2011).

https://doi.org/10.1016/j.jare.2011.01.008

[2] Taha A. A., Wu Y-N., Wang H., Li F.: Preparation and application of functionalized cellulose acetate/silica composite nanofibrous membrane via electrospinning for $\mathrm{Cr}(\mathrm{VI})$ ion removal from aqueous solution. Journal of Environmental Management, 112, 10-16 (2012). https://doi.org/10.1016/j.jenvman.2012.05.031

[3] Papageorgiou S. K., Katsaros F. K., Kouvelos E. P., Nolan J. W., Le Deit H., Kanellopoulos N. K.: Heavy metal sorption by calcium alginate beads from Laminaria digitata. Journal of Hazardous Materials, 137, 1765-1772 (2006).

https://doi.org/10.1016/j.jhazmat.2006.05.017

[4] Mokhena T., Jacobs V., Luyt A. S.: A review on electrospun bio-based polymers for water treatment. Express Polymer Letters, 9, 839-880 (2015). https://doi.org/10.3144/expresspolymlett.2015.79 
[5] Kamsonlian S., Suresh S., Majumder C., Chand S.: Characterization of banana and orange peels: Biosorption mechanism. International Journal of Science Technology and Management, 2, 1-7 (2011).

[6] Pandey A., Bera D., Shukla A., Ray L.: Studies on $\mathrm{Cr}(\mathrm{VI}), \mathrm{Pb}(\mathrm{II})$ and $\mathrm{Cu}(\mathrm{II})$ adsorption-desorption using calcium alginate as biopolymer. Chemical Speciation and Bioavailability, 19, 17-24 (2007).

https://doi.org/10.3184/095422907X198031

[7] Haider S., Park S-Y.: Preparation of the electrospun chitosan nanofibers and their applications to the adsorption of $\mathrm{Cu}(\mathrm{II})$ and $\mathrm{Pb}(\mathrm{II})$ ions from an aqueous solution. Journal of Membrane Science, 328, 90-96 (2009).

https://doi.org/10.1016/j.memsci.2008.11.046

[8] Saeed K., Haider S., Oh T-J., Park S-Y.: Preparation of amidoxime-modified polyacrylonitrile (PAN-oxime) nanofibers and their applications to metal ions adsorption. Journal of Membrane Science, 322, 400-405 (2008). https://doi.org/10.1016/j.memsci.2008.05.062

[9] Ki C. S., Gang E. H., Um I. C., Park Y. H.: Nanofibrous membrane of wool keratose/silk fibroin blend for heavy metal ion adsorption. Journal of Membrane Science, 302, 20-26 (2007).

https://doi.org/10.1016/j.memsci.2007.06.003

[10] Aliabadi M., Irani M., Ismaeili J., Piri H., Parnian M. J.: Electrospun nanofiber membrane of $\mathrm{PEO} /$ chitosan for the adsorption of nickel, cadmium, lead and copper ions from aqueous solution. Chemical Engineering Journal, 220, 237-243 (2013). https://doi.org/10.1016/j.cej.2013.01.021

[11] Xiang T., Zhang Z., Liu H., Yin Z., Li L., Liu X.: Characterization of cellulose-based electrospun nanofiber membrane and its adsorptive behaviours using $\mathrm{Cu}(\mathrm{II})$, $\mathrm{Cd}(\mathrm{II}), \mathrm{Pb}(\mathrm{II})$ as models. Science China Chemistry, 56, 567-575 (2013).

https://doi.org/10.1007/s11426-012-4783-7

[12] Patanaik A., Jacobs V., Anandjiwala R.: Performance evaluation of electrospun nanofibrous membrane. Journal of Membrane Science, 352, 136-142 (2010).

https://doi.org/10.1016/j.memsci.2010.02.009

[13] Haider S., Park S-Y.: Preparation of the electrospun chitosan nanofibers and their applications to the adsorption of $\mathrm{Cu}$ (II) and $\mathrm{Pb}$ (II) ions from an aqueous solution. Journal of Membrane Science, 328, 90-96 (2009). https://doi.org/10.1016/j.memsci.2008.11.046

[14] Babel S., Kurniawan T. A.: Low-cost adsorbents for heavy metals uptake from contaminated water: A review. Journal of Hazardous Materials, 97, 219-243 (2003). https://doi.org/10.1016/S0304-3894(02)00263-7

[15] Zhu H., Fu Y., Jiang R., Yao J., Xiao L., Zeng G.: Optimization of copper(II) adsorption onto novel magnetic calcium alginate/maghemite hydrogel beads using response surface methodology. Industrial and Engineering Chemistry Research, 53, 4059-4066 (2014). https://doi.org/10.1021/ie4031677
[16] Ozdemir G., Ceyhan N., Manav E.: Utilization in alginate beads for $\mathrm{Cu}(\mathrm{II})$ and $\mathrm{Ni}(\mathrm{II})$ adsorption of an exopolysaccharide produced by Chryseomonas luteola TEM05. World Journal of Microbiology and Biotechnology, 21, 163-167 (2005). https://doi.org/10.1007/s11274-004-1563-3

[17] Islam M. S., Ashaduzzaman M., Masum S. M., Yeum J. H.: Mechanical and electrical properties: Electrospun alginate/carbon nanotube composite nanofiber. Dhaka University Journal of Science, 60, 125-128 (2012). https://doi.org/10.3329/dujs.v60i1.10350

[18] Bhattarai N., Li Z., Edmondson D., Zhang M.: Alginate-based nanofibrous scaffolds: Structural, mechanical, and biological properties. Advanced Materials, 18, 1463-1467 (2006). https://doi.org/10.1002/adma.200502537

[19] Pucić I., Jurkin T.: FTIR assessment of poly(ethylene oxide) irradiated in solid state, melt and aqeuous solution. Radiation Physics and Chemistry, 81, 1426-1429 (2012). https://doi.org/10.1016/j.radphyschem.2011.12.005

[20] Bhattarai N., Zhang M.: Controlled synthesis and structural stability of alginate-based nanofibers. Nanotechnology, 18, 455601/1-455601/11 (2007).

https://doi.org/10.1088/0957-4484/18/45/455601

[21] Liu H., Feng S., Zhang N., Du X., Liu Y.: Removal of $\mathrm{Cu}$ (II) ions from aqueous solution by activated carbon impregnated with humic acid. Frontiers of Environmental Science and Engineering, 8, 329-336 (2014). https://doi.org/10.1007/s11783-013-0553-9

[22] Adeli M., Yamini Y., Faraji M.: Removal of copper, nickel and zinc by sodium dodecyl sulphate coated magnetite nanoparticles from water and wastewater samples. Arabian Journal of Chemistry, 10, S514-S521 (2017). https://doi.org/10.1016/j.arabjc.2012.10.012

[23] Hu X-J., Wang J-S., Liu Y-G., Li X., Zeng G-M., Bao Z-L., Zeng X-X., Chen A-W., Long F.: Adsorption of chromium(VI) by ethylenediamine-modified crosslinked magnetic chitosan resin: Isotherms, kinetics and thermodynamics. Journal of Hazardous Materials, 185, 306-314 (2011).

https://doi.org/10.1016/j.jhazmat.2010.09.034

[24] Aly Z., Graulet A., Scales N., Hanley T.: Removal of aluminium from aqueous solutions using PAN-based adsorbents: Characterisation, kinetics, equilibrium and thermodynamic studies. Environmental Science and Pollution Research, 21, 3972-3986 (2014).

https://doi.org/10.1007/s11356-013-2305-6

[25] Desta M. B.: Batch sorption experiments: Langmuir and Freundlich isotherm studies for the adsorption of textile metal ions onto teff straw (Eragrostis tef) agricultural waste. Journal of Thermodynamics, 2013, 375830/1375830/6 (2013).

https://doi.org/10.1155/2013/375830 
[26] Huang C., Chung Y-C., Liou M-R.: Adsorption of Cu(II) and $\mathrm{Ni}(\mathrm{II})$ by pelletized biopolymer. Journal of Hazardous Materials, 45, 265-277 (1996).

https://doi.org/10.1016/0304-3894(95)00096-8

[27] Bassi R., Prasher S. O., Simpson B.: Removal of selected metal ions from aqueous solutions using chitosan flakes. Separation Science and Technology, 35, 547560 (2000).

https://doi.org/10.1081/SS-100100175
[28] Monser L., Adhoum N.: Modified activated carbon for the removal of copper, zinc, chromium and cyanide from wastewater. Separation and Purification Technology, 26, 137-146 (2002). https://doi.org/10.1016/S1383-5866(01)00155-1

[29] Kalmykova Y., Stömvall A-M., Steenari B-M.: Adsorption of $\mathrm{Cd}, \mathrm{Cu}, \mathrm{Ni}, \mathrm{Pb}$ and $\mathrm{Zn}$ on Sphagnum peat from solutions with low metal concentrations. Journal of Hazardous Materials, 152, 885-891 (2008). https://doi.org/10.1016/j.jhazmat.2007.07.062 